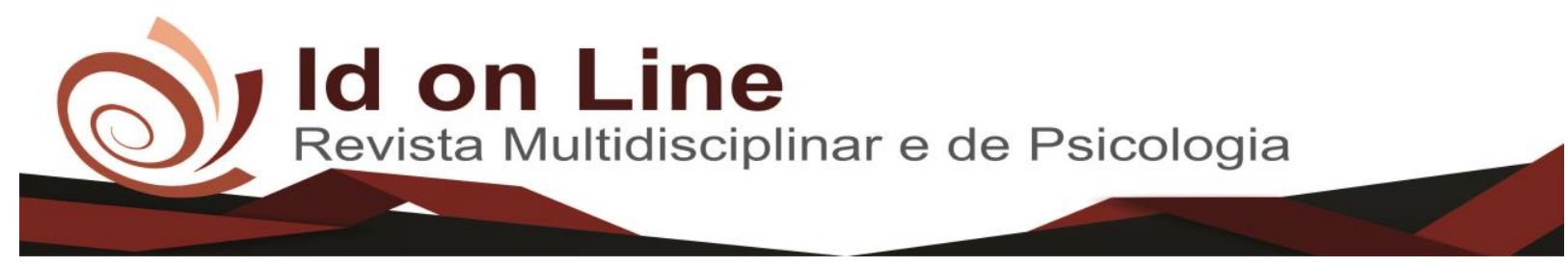

Artigo

\title{
A Importância da Qualidade do Atendimento na Prestação de Serviços no Setor Público
}

\author{
Eduardo Alves Castro ${ }^{1}$
}

\begin{abstract}
Resumo: O atendimento é uma questão de sobrevivência nos segmento de mercado em que os recursos tecnológicos estão cada vez mais acessíveis e equalizados, portanto sua eficácia tem relação direta com o nível de satisfação dos clientes. A ineficiência do atendimento causa insatisfação e se torna um risco incalculável para as instituições. O objetivos do artigo será a busca de uma reflexão sobre a qualidade no atendimento nos serviços públicos, demonstrar a importância do atendimento de qualidade para estas instituições, explanar métodos de implantação e concluir que é possível mudar o estigma e o preconceito existente com relação ao atendimento aos clientes nos órgãos públicos.
\end{abstract}

Palavras-chave: Atendimento, público, qualidade, satisfação.

\section{The Importance of the Quality of Attendance in the Provision of Services in the Public Sector}

\begin{abstract}
The attendance is an important metter when it comes to the surviving on the Market where technological resources are more accessible and equalized, therefore its efficiency is directly related with the clients satisfaction levels. The inefficiency on the attendance causes insatisfaction and becomes an incalculable risk to the institutions. The objective on this article is to search a reflection on the attendance quality on the public institutions, showing how important is a high quality attendance on the public servisse, explaning methods to implant and conclude that it is possible to change the stigma and the preconception that is common when it comes to public opinion about clients attendance on public institutions.
\end{abstract}

Key-words: Attendance, public, quality, Satisfaction.

\footnotetext{
${ }^{1}$ Bacharel em Administração pela Faculdade Sete de Setembro-FASETE. Pós-Graduado pela Universidade do Sul de Santa Catarina-UNISUL. Pós-Graduando pela Universidade Federal do Vale do São Francisco-UNIVASF.

Contato: eduardo-castro@hotmail.com
} 


\section{Introdução}

A globalização, a integração e a velocidade de comunicação afetaram a postura do consumidor, que hoje exige desempenho ótimos de produtos e serviços, sem a mínima tolerância com relação a de tempo, falhas ou qualidade do produto ou serviço prestado.

Todos esses motivos apontam o cuidado que se deve ter em relação ao atendimento aos clientes, muitas organizações e instituições ainda não perceberam a realidade, o comportamento e as tendências de mercado, no que diz respeito ao valor da conquista e preservação de um cliente. Conquistar clientes, sempre foi uma tarefa difícil e desafiadora, mantê-los fiéis, requer uma condição muito mais aprimorada e o atendimento de qualidade pode ser a chave ou o elo que falta para se alcançar esse objetivo.

Hoje em dia os clientes estão, pode-se dizer mais espertos e mais preparados, fazem pesquisas, avaliação de preços, troca de informações, contenção da impulsividade de consumo e principalmente defesa de seus direitos. Exigências que eram privilégios apenas dos clientes mais conservadores, hoje, fazem parte das condições mínimas de satisfação, com isso a postura das instituições precisa e deve urgentemente passar por mudanças na busca de ajustes de padrões mais adequados, ajustes estes que ofereçam produtos e serviços com qualidade para um cliente cada vez mais exigente.

A principal função do serviço público é atender à demanda da população, independente do setor de atendimento. As áreas da educação, saúde , administrativa e outras, fazem a esfera pública funcionar. Nesse contexto, o contato primário do público com um desses setores é realizado com algum atendente, seja de forma presencial ou por telefone.

As falhas no atendimento têm normalmente duas origens: a falta de um padrão no atendimento e a falta de amplitude na capacitação dos funcionários. $\mathrm{O}$ padrão de atendimento representa a marca registrada da instituição, seja ela pública ou não.

A qualidade no serviço prestado é um sinônimo de eficácia, é a capacidade de atender a uma necessidade, ou alterar para melhor uma situação por exemplo um estado de saúde, de educação. Sendo a qualidade do serviço prestado fortemente associada a sua capacidade de proporcionar satisfação as necessidades do usuário, consumidor ou cliente, na sua mensuração é fundamental considerar-se a forma ou a maneira com que eles percebem ou sentem a 
satisfação de suas necessidades. Isso deixa claro que a qualidade foi o agente de mudança corporativa mais importante do novo milênio e é a demanda gerencial mais importante a ser enfrentada pelas instituições. Portanto o objetivo desse estudo é demonstrar a importância da qualidade no atendimento e na prestação de serviços para estas instituições, deixar clara a relevância da capacitação das pessoas envolvidas e do padrão de atendimento.

\section{Referencial Teórico}

\section{Qualidade no atendimento}

Segundo Kotler (2000) a qualidade total é a chave para a criação de valor e satisfação dos clientes; e Paladini (1995, p.188), afirma que:

Se for verdade que a qualidade começa e termina no cliente, também é verdade que a qualidade é projetada, é desenvolvida e gerada no processo. E isto independe do tipo de produto que estamos falando - se bens tangíveis, métodos ou serviços.

A definição de Kotler (2000, p.78) é da qualidade claramente voltada para o cliente: qualidade é a totalidade dos atributos e características de um produto ou serviço, que afetam sua capacidade de satisfazer necessidades declaradas ou implícitas. A qualidade é o mínimo que o cliente espera de qualquer produto ou serviço. Se não houver qualidade, fatalmente não haverá relacionamento, porque não haverá recompra. Justifica-se o enfoque da qualidade por ser componente essencial para a formulação de políticas e estratégicas de excelência e relacionamentos em qualquer tipo de organização.

Nesta visão Kotler (1998, p.65) define: "Qualidade é, a totalidade de aspectos e características de um produto ou serviço, que proporcionam a satisfação das necessidades declaradas e implícitas". O autor quer mostrar que nem sempre o cliente explicita tudo o que quer. 
De acordo com Almeida (2001) existem sete pecados com relação ao atendimento ao cliente que podem gerar insatisfação no mesmo diminuindo o grau de qualidade no atendimento prestado. Tais pecados são:

1) Apatia - Se caracteriza quando funcionários ou servidores não se mostram interessados nos problemas dos clientes, gerando muita insatisfação;

2) Má vontade - Ocorre quando os funcionários tentam se livrar do cliente sem resolver seus problemas;

3) Frieza - Se refere a forma de tratamento do funcionário para com os clientes, quando o mesmo é tratado de forma fria e distante;

4) Desdém - Quando o funcionário se dirige ao cliente de cima para baixo, com se ele não soubesse nada;

5) Robotismo - Acontece quando o funcionário deixa de agir como uma pessoa e repete sempre a mesma coisa, se mostrando distante e repetitivo.;

6) Demasiado apego as normas - Se dá quando o funcionário ou servidor fica muito bitolado as normas se tornando inflexível;

7) Jogo de responsabilidades - Ocorre quando os funcionários mandam o cliente de um setor para outro sem resolver seus problemas.

\section{Personalização do atendimento}

De acordo com Azevedo e Pomeranz (2004, p.43) a personalização corresponde a "capacidade de comunicar-se com o consumidor de maneira individualizada em contraposição a uma solução massificada que trata todas as pessoas da mesma maneira”. A doutrina do atendimento com base na adequação ao perfil do cliente tem um valor imbatível quando agregado aos serviços. A personalização vai além do tratamento pelo nome, mas na postura adequada e adaptada da empresa/instituição procurando invariavelmente vivenciar o sonho do cliente. 
A personalização dos serviços evidencia que a instituição reconhece que o cliente é uma entidade única, com necessidade e desejos muito particulares, sendo que quanto maior for sua satisfação, maiores serão as possibilidades de fidelização deste cliente. Azevedo e Pomeranz (2004, p.44) ressaltam ainda que "a tecnologia serve de ajuda neste caso, tanto no suporte para a construção de grandes bancos de dados como na personalização de conteúdo".

\section{Encantamento de clientes}

Apenas satisfazer os desejos dos clientes já é considerado um modelo trivial, considerando os padrões de competitividade do mercado. Superar expectativas principalmente no âmbito de serviços agregados é um modelo de sucesso incontestável. O cliente deve ser surpreendido por condições especiais de negócios que ele não espera e, principalmente, que ele não tenha de pagar mais por isso.

De acordo com Cobra (2001, p.148) "Para encantar um cliente é preciso ir além de satisfazer suas necessidades. É preciso surpreendê-los realizando desejos explícitos e até mesmo desejos ocultos".

Cobra (2003) Enfatiza ainda que para levar o cliente ao encantamento, não basta oferecer exclusivamente benefícios financeiros, é importante também oferecer mais dois tipos de benefícios: sociais e estruturais.

O papel do atendimento para o encantamento de clientes é muito importante e os atendentes devem estar preparados para superar as expectativas dos clientes nos mínimos detalhes e o esforço nesse sentido é que diferenciará o atendimento superior ao trivial.

\section{A importância da qualidade em serviços}

Gerenciar o movimento pela qualidade dos serviços é uma evolução que necessariamente avança a cada dia, já que diariamente aprende-se como incorporá-la melhor às 
atividades das instituições. A importância desse gerenciamento é traduzida pela afirmação de Gale (1996, p.103) "serviço ao cliente, de alta qualidade, significa lucros”. Essa flexibilização nos serviços é necessária. No conceito de Paladini (2000) o atendimento ao cliente depende das expectativas que ele demonstra ou expressa durante a relação existente no processo. Para tanto, é necessária extrema flexibilidade, criatividade e capacidade de adaptação.

A melhoria contínua na qualidade é fator de competitividade essencial para que a instituição enfrente a disputa direta no mercado de seus produtos e serviços. Berry (2001, p.13) afirma que "a confiança do cliente é o ativo mais precioso que qualquer instituição pode ter e a excelente execução do serviço dia após dia á um elemento fundamental na construção de confiança".

Para Levitt (1990, p.126), o relacionamento entre vendedor e comprador raramente termina após a venda. Na realidade este relacionamento intensifica-se e torna-se o fator crítico na escolha do consumidor para uma próxima compra.

\section{Treinamento de pessoal para atendimento ao público}

Hoje em dia, para se conseguir um atendimento em excelência é indispensável o treinamento dos funcionários e implantação de modelos de atendimento ideais, pois é crescente a preocupação com a qualificação de cada funcionário envolvido direta ou indiretamente com o atendimento, a qualificação é uma ferramenta de grande importância, pois quando o colaborador conhece bem os produtos e serviços oferecidos pela instituição fica bem mais fácil adequá-los as necessidades e desejos dos clientes, conseguindo realizar um atendimento rápido, qualificado e além das expectativas.

A função do treinamento é maximizar a eficácia e o desenvolvimento organizacional e consequentemente obter lucro. A formação transmitida durante o treinamento deverá contribuir positivamente para os resultados do negócio:

Direta ou indiretamente,

- A curto, médio ou longo prazo. 
Segundo Chiavenatto (1999,p.237) treinamento é o processo de ensinar aos novos empregados as habilidades básicas que eles necessitam para desempenhar seus cargos de maneira excelente. Um dos principais propósitos do treinamento é aumentar a produtividade dos indivíduos em seus cargos, influenciando seus comportamentos, segundo o autor os programas focados em resultados abrangem quatro pontos principais:

1 - Buscar transmitir informações relevantes sobre a organização (seu ambiente interno e externo), missão, visão, políticas, regulamentos e clientes.

2 - Desenvolver as capacidades profissionais dos participantes para que possam contribuir mais eficazmente para o propósito da instituição; Melhorar e desenvolver novas habilidades para execução das tarefas, principalmente de olhos nos avanços que a tecnologia oferece.

3 - Desenvolver, nos participantes comportamentos e atitudes que lhes permitam ter maior eficiência, eficácia e satisfação profissional no exercício da sua atual função Promover conscientização que promova a transformação de atitudes que sejam desfavoráveis, como falta de entusiasmo, alteridade e consciência organizacional perante os clientes internos e externos.

4 - Buscar novos conhecimentos, conceitos e ideias; o pluralismo, a versatilidade e o dinamismo são características fundamentais nos dias atuais, para manter uma instituição conectada com mercado atual e empregabilidade de todos.

Os resultados de programas de treinamento podem ser vistos e mensurados no cotidiano das instituições por meio da redução dos custos, melhoria da qualidade dos produtos, satisfação dos funcionários e principalmente no atendimento aos clientes, tendo como resultado a satisfação dos mesmos além de aumentar a produtividade, os investimentos em novas pesquisas e treinamentos do pessoal.

Dantas (2004, p.123) define algumas premissas relacionadas ao treinamento de atendentes:

O treinamento de atendentes e de profissionais que lidam constantemente e diretamente com o público é um empreendimento que deve ser conduzido em conjunto por treinandos e instrutores.

O treinamento desses profissionais não é uma atividade fortuita, feita apenas uma vez. Deve ter prosseguimento no próprio trabalho e, mesmo, em periódicos retornos a um ambiente de estudo e reflexão, para atualização e revisão de alguns pontos. 
Os empresários, dirigentes, chefes e supervisores têm papel importantíssimo antes, durante e após o treinamento.

Segundo Dantas (2004, p.124) "Um programa de treinamento na área de atendimento ao público deve envolver todos os empregados da organização que têm contato habitual com o público na prestação de atendimento, qualquer que seja sua função".

Com base nessa citação pode-se incluir: Recepcionistas, telefonistas, operadores de call center, ascensoristas, atendentes propriamente ditos, secretárias, supervisores e chefes.

Aspectos de um atendimento diferenciado são citados por Kotler (1998, p. 89). Segundo ele, Pessoas bem treinadas exibem seis características:

Competência: colaboradores possuem experiência conhecimentos exigidos;

Cortesia: são amigáveis, respeitosos e ponderados;

Credibilidade: são dignos de crédito;

Confiabilidade: desempenham o serviço com consistência e cuidado;

Responsividade: respondem rapidamente às solicitações e aos problemas dos consumidores;

Comunicação: "se esforçam para entender o cliente e para comunicar-se claramente".

Portanto, o treinamento é um processo contínuo de melhoria das competências do funcionário, Investir no seu principal ativo, as pessoas, é uma realidade presente e indiscutível, afinal são as pessoas que representam o negócio e a imagem de uma instituição.

\section{Procedimentos Metodológicos}

O método certifica uma pesquisa tornando-a uma pesquisa cientifica. Segundo Triviños (1987), o valor científico dos achados do investigador dependerá, fundamentalmente, do modo como se faz a descrição do que se observa. Para Barros e Lehfeld (2000, p.47) “o conhecimento obtido pela investigação cientifica contribui para a aplicação do conhecimento acumulado, e para a construção, reformulação e transformação das teorias científicas”.

A metodologia para este artigo foi desenvolvida com base principalmente em livros, caracterizando uma pesquisa bibliográfica que segundo Prestes (2002, p.24) “A pesquisa 
bibliográfica é aquela que se efetiva tentando resolver um problema ou adquirir conhecimento a partir do emprego predominante de informações provenientes de material gráfico, sonoro ou informatizado". Para Barros e Lehfeld (2000) a pesquisa bibliográfica é de grande eficácia porque "permite obter uma postura cientifica quanto à elaboração de informações da produção cientifica já existente, à elaboração de relatórios e à sistematização do conhecimento". Através destes contatos bibliográficos e documentações preliminares foi possível o contato com o campo de pesquisa e melhor definição do estudo a ser realizado.

As pesquisas que foram realizadas são consideradas exploratórias e descritivas, que de acordo com Mattar (1999), são caracterizadas por possuírem um objetivo definido, serem bem estruturadas e dirigidas para a solução de problemas ou avaliação de alternativas de cursos e ações. Lakatos e Marconi (1991) deixam claro que pesquisa exploratório-descritiva se caracteriza por uma investigação que objetiva uma descrição completa de um determinado fenômeno.

$\mathrm{Na}$ coleta de dados o método utilizado foi o questionário, pois de acordo com Mattar (1994), é um dos instrumentos mais utilizados nas pesquisas exploratórias e descritivas. Lakatos e Marconi (1991) definem o questionário como uma série ordenada de perguntas que podem ser qualificadas como abertas (livres ou não limitadas), fechadas ou dicotômicas (limitadas ou de alternativas fixas) e de múltipla escolha (perguntas fechadas com mais de duas alternativas fixas).

\section{Resultados e discussões}

Pesquisa realizada aleatoriamente com pessoas que responderam afirmativamente para a seguinte pergunta: Você já recebeu atendimento presencial em uma instituição pública? Obtive o seguinte resultado com relação a questionamentos que se referem a itens que influem diretamente no atendimento de qualidade, além de constatar a opinião com relação a satisfação de modo geral das pessoas com o atendimento prestado nas instituições públicas. 
Gráfico 1: Suficiência em relação à quantidade de servidores no atendimento.

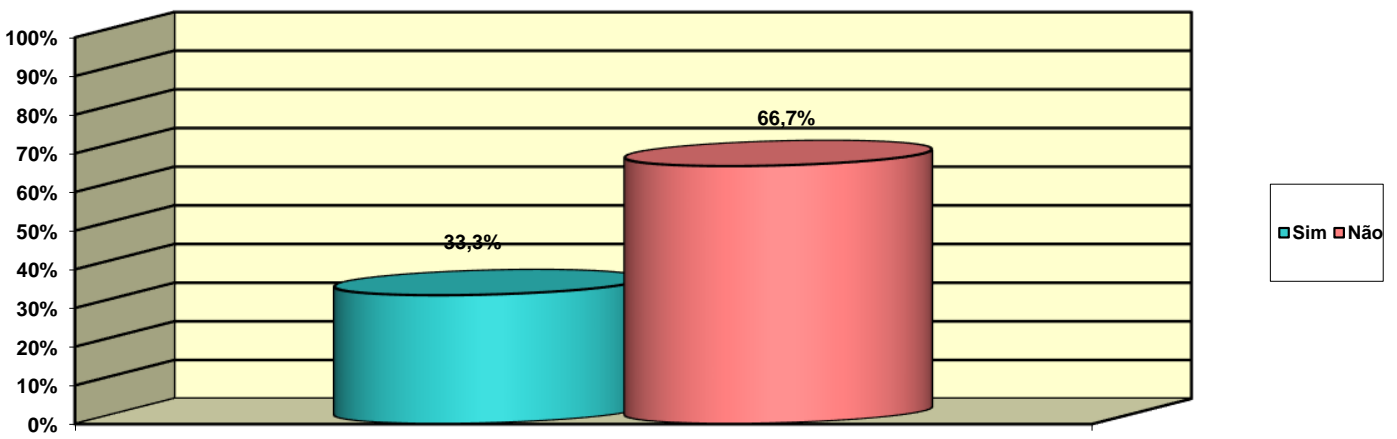

Analisando o gráfico 1, observou-se que a maioria das pessoas, não estão satisfeitas com relação à quantidade de servidores destinados ao atendimento nas instituições públicas, onde $66,7 \%$ afirmaram que a quantidade atual não é suficiente e 33,3\% afirmaram que a quantidade de funcionários no atendimento é suficiente.

Las Casas (2000, p.36) diz que:

As expectativas são muitas e, não sendo atendidas podem ser causas do fracasso do empreendimento; a lealdade que foi adquirida começa a desaparecer no momento em que o nível de serviço diminui. Para o consumidor o que importa é a solução de seus problemas.

Portanto um cliente que procura resolver seus problemas e se depara com um número insuficiente de servidores no atendimento, tende a se insatisfazer, pois seus problemas demorarão a ser resolvidos.

Gráfico 2: Conhecimento de formas alternativas de atendimento.

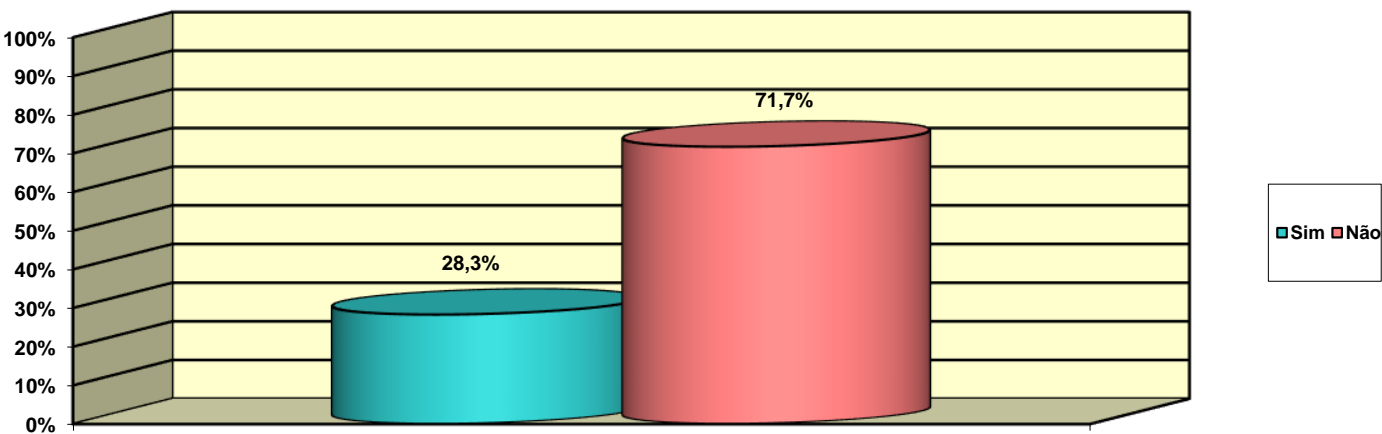


Indagados com relação ao conhecimento de formas alternativas de atendimento como: atendimento telefônico ou via internet, $71,7 \%$ das pessoas questionadas responderam que não tinham conhecimento da existência de tais formas de atendimento e $28,3 \%$ disseram que não conheciam.

De acordo com Almeida (2001) o ideal para uma instituição é disponibilizar todos os canais possíveis para o cliente e que todos esses canais estejam interligados em uma única base de dados. Isso facilitaria a vida do cliente, pois não interromperia o fluxo de atendimento, seja qual fosse o canal usado. Porém de acordo com (DENTON apud ALMEIDA 2001 p.115) "a tecnologia é uma ferramenta para ajudar as pessoas e não para substituí-las", ou seja apesar de a maioria das pessoas conhecerem e fazerem uso dos canais alternativos de atendimento todos precisam das pessoas no atendimento, uns por opção outros por não adequação a tecnologia, portanto as pessoas são imprescindíveis no atendimento.

Gráfico 3: Satisfação quanto à capacitação do funcionário de atendimento.

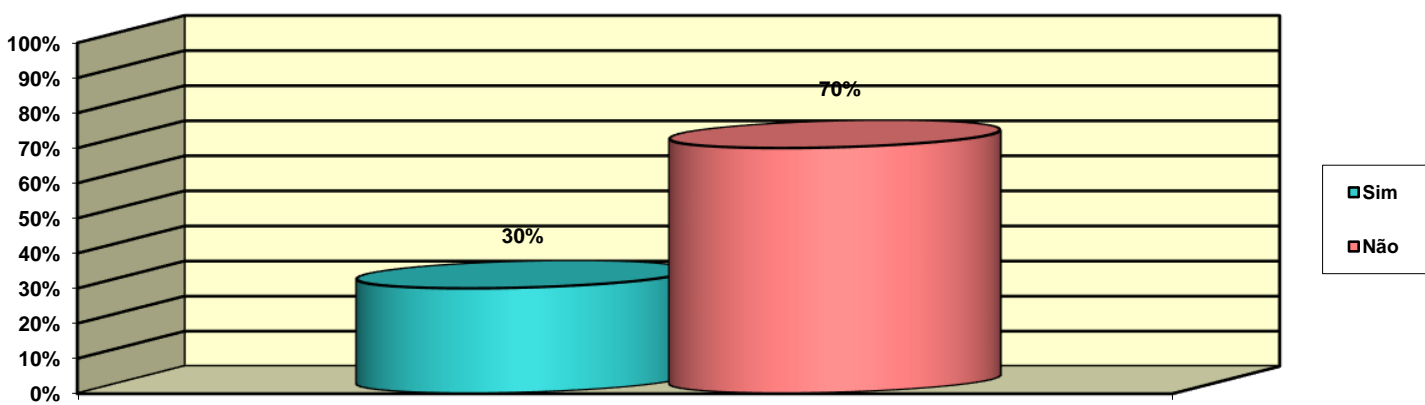

No gráfico 3, 30\% dos das pessoas questionadas dizem que através de sua percepção com relação ao treinamento dos servidores da linha de frente estão que estão satisfeitas inclusive que os mesmos estão capacitados para realizar tal função, já para $70 \%$ dos clientes, tais servidores não correspondem a suas exigências e não estão capacitados para exercer a função.

Las Casas (2000 p.168) diz que:

O treinamento é essencial, pois, praticamente todas as características dos serviços devem ser abordadas com o treinamento. O problema da intangibilidade pode ser resolvido com o nível de profissionalismo adequado, o que resulta na formação da imagem. 
Gráfico 4 - Grau de satisfação do atendimento prestado pelos servidores.

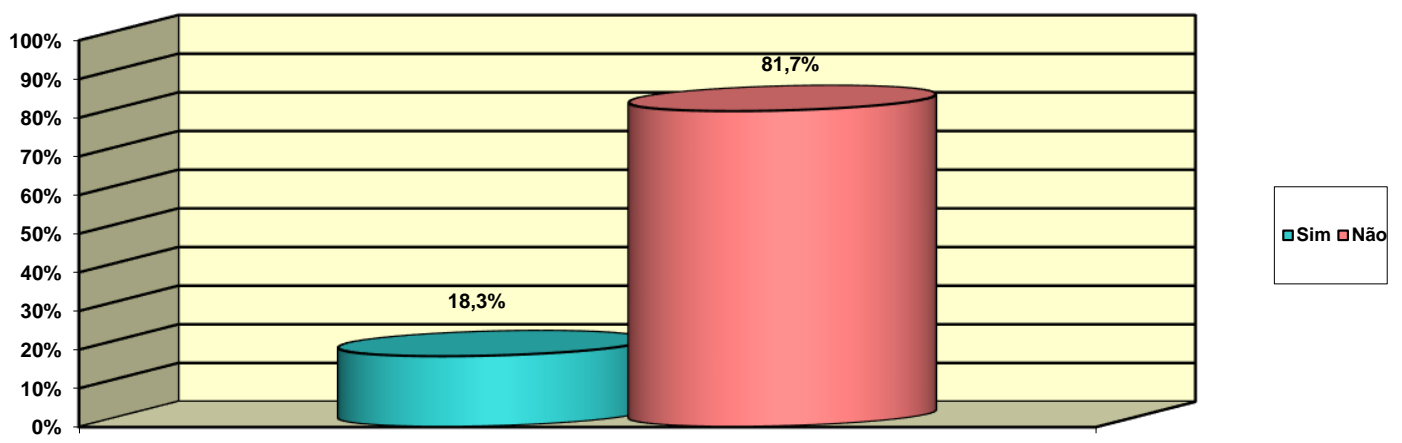

No gráfico 04, constatou-se que quando perguntados em relação a satisfação quanto ao atendimento na instituição pública que teve experiência, $81,7 \%$ dos clientes responderam que não estão satisfeitos e 18,3\% disseram que sim, estava satisfeitos com o atendimento prestado.

Almeida (2001) deixa claro que servindo bem, cria-se de forma natural a obrigação dos outros retribuírem, seja em forma de elogio, recomendação ou reconhecimento. E como o gráfico mostra, é preocupante o nível de insatisfação, mostra que há muito o que ser melhorado para que aconteça uma mudança nesse cenário.

De acordo com Kotler (1998 p.53) "satisfação é o sentimento de prazer ou de desapontamento resultante de comparação do desempenho esperado pelo produto (ou resultado) em relação às expectativas das pessoas”.

\section{Considerações finais}

Com o referente estudo, conclui-se que não existe uma fórmula mágica que solucione a situação do atendimento no setor público, contudo a adoção de estratégias poderá vir ao encontro de significativos resultados. Em primeiro lugar a questão do atendimento a clientes deve estender-se além do âmbito das preocupações e ocupar definitivamente o campo das ações práticas e efetivas. 
O círculo de qualidade implica um grupo de pessoas que se reúnem regularmente para discutir os meios de melhorar a qualidade de seus produtos e serviços (CHIAVENATO, 2000).

Como sugestões estratégicas podem-se citar ações de melhoria como adotar um trabalho com os servidores chamado de qualidade contínua do atendimento ou círculo de qualidade, dentro da instituição incluindo todos os níveis hierárquicos. É preciso educar os servidores antes de treiná-los em habilidades com foco de relações humanas.

O envolvimento dos servidores na busca de soluções de qualidade constitui um aspecto fundamental nos processos de melhoria. Para que a mesma seja contínua, é preciso que as pessoas procurem sempre o aperfeiçoamento e nunca a acomodação, que é uma das reclamações por parte dos clientes. Uma boa forma de combinar o envolvimento das pessoas com a melhoria contínua é a utilizar-se do conceito de círculos de qualidade.

Outra sugestão seria aumentar o número de servidores e atendentes, principalmente nos horários de pico, tal medida poderia ser aplicada com a contratação de novos servidores concursados ou deslocar servidores de outros setores para setores críticos, com o intuito de gerar maior agilidade e eficiência ao atendimento, já que na pesquisa de campo ficou evidente a insatisfação do cliente em relação a esse fator.

Tais medidas tornaria notável o crescimento da satisfação do cliente, pois, será atendido em menos tempo, com melhor qualidade, e com mais agilidade, pois, a instituição teria uma maior quantidade de servidores para executar as atividades, maior divisão de tarefas, tirando um pouco da carga de trabalho dos mesmos, teria a potencialização do lucro por conta da maior quantidade de clientes atendidos num menor período de tempo.

Outra sugestão plausível seria intensificar o treinamento e capacitação dos servidores tornando-os plenamente capacitados para exercer a função de atendimento. Tais cursos seriam voltados à qualidade no atendimento, sempre em busca da excelência e satisfação do cliente, o objetivo é tornar os servidores competitivos, para se manterem em atividade e terem sempre excelente nível no atendimento, na qualidade e na produtividade, buscando oferecer um atendimento ágil e eficaz, deixando a disposição do cliente conteúdos com soluções personalizadas de apoio e suporte adequadas às necessidades de cada cliente, além de um atendimento com mais clareza, educação, qualidade e de forma mais humana. 


\section{Referências}

ALMEIDA, Sérgio. Ah! Eu não acredito; como cativar o cliente através de um fantástico atendimento $104^{\circ} \mathrm{ed}$. Salvador: Casa da qualidade, 2001.

AZEVEDO, Abaeté; POMERANZ, Ricardo. Marketing de Resultados. São Paulo: M. Books, 2004.

BARROS, A. J. P. , LEHFELD, N. A. S. Fundamentos de metodologia: um guia para a iniciação cientifica. 2.ed. São Paulo: Makron Books, 2000.

BERRY, L. Descobrindo a essência do serviço: os novos geradores de sucesso sustentável nos negócios. Rio de Janeiro: Qualitymark, 2001.

CHIAVENATO, Idalberto.Gestão de Pessoas; o novo papel dos recursos humanos nas organizações. Rio de Janeiro: Campus, 1999.

CHIAVENATO, Idalberto. Administração nos Novos Tempos. $6^{\circ}$ ed. Rio de Janeiro: Campus, 2000.

COBRA, Marcos. Estratégias de Marketing de serviços. São Paulo: Cobra, 2001.

Administração de Marketing no Brasil. São Paulo: Cobra, 2003.

DANTAS, Edmundo Brandão. Atendimento ao público nas organizações: Quando o marketing de serviços mostra a cara. Brasília: SENAC, 2004.

GALE, B. T. Gerenciando o valor do cliente. São Paulo: Pioneira, 1996;

KOTLER, P. Administração de marketing: Análise, planejamento, implementação e controle. $5^{\circ}$ ed. São Paulo: Atlas, 1998.

LAKATOS, Eva Maria; MARCONI, Marina de Andrade. Fundamentos de Metodologia Cientifica. $3^{\circ}$ ed. São Paulo: Atlas, 1991.

LAS CASAS, Alexandre L. Marketing de Serviços. $2^{\circ}$ ed. Editora Atlas. São Paulo, 2000.

LEVITT, T. A imaginação de Marketing. $2^{\circ}$ ed. São Paulo: Atlas, 1990.

MATTAR, Frauze N. Pesquisa de Marketing, São Paulo: Atlas, 1994.

Pesquisa de Marketing: metodologia e planejamento. São Paulo: Atlas,1999. 
PALADINI, Edson Pacheco.Gestão da Qualidade no Processo: A Qualidade na Produção de Bens e Serviços. São Paulo: Atlas,1995.

Gestão da qualidade: teoria e prática. São Paulo: Atlas, 2000.

PRESTES, Maria Luci de Mesquita. A pesquisa e a construção do conhecimento científico. São Paulo: Respel,2002.

TRIVIÑOS, A. N. S. Introdução à pesquisa em ciências sociais: a pesquisa qualitativa em educação. São Paulo: Atlas, 1987.

Como citar este artigo (Formato ABNT):

CASTRO, Eduardo Alves. A Importância da Qualidade do Atendimento na Prestação de Serviços no Setor Público. Id on Line Rev.Mult. Psic., 2018, vol.12, n.41, p.470-484. ISSN: 1981-1179.

Recebido: 16/06/2018

Aceito 28/06/2018 